Journal of Patient-Centered

$1-30-2015$

\title{
Association Between Body Surface Area and Outcomes After Percutaneous Coronary Intervention
}

Kambiz Shetabi

Tonga Nfor

Fengyi Shen

Anjan Gupta

Tanvir Bajwa

Suhail Allaqaband

Follow this and additional works at: https://aah.org/jpcrr

Part of the Cardiology Commons, Cardiovascular Diseases Commons, Cardiovascular System Commons, and the Medical Anatomy Commons

\section{Recommended Citation}

Shetabi K, Nfor T, Shen F, Gupta A, Bajwa T, Allaqaband S. Association between body surface area and outcomes after percutaneous coronary intervention. J Patient Cent Res Rev. 2015;2:9-16. doi: 10.17294/ 2330-0698.1048

Published quarterly by Midwest-based health system Advocate Aurora Health and indexed in PubMed Central, the Journal of Patient-Centered Research and Reviews (JPCRR) is an open access, peer-reviewed medical journal focused on disseminating scholarly works devoted to improving patient-centered care practices, health outcomes, and the patient experience. 


\title{
Association Between Body Surface Area and Outcomes After Percutaneous Coronary Intervention
}

\author{
*Kambiz Shetabi, MD, *Tonga Nfor, MD, MSPH, Fengyi Shen, MD, Anjan Gupta, MD, \\ Tanvir Bajwa, MD, Suhail Allaqaband, MD \\ Aurora Cardiovascular Services, Aurora Sinai/Aurora St. Luke's Medical Centers, University of Wisconsin School of \\ Medicine and Public Health, Milwaukee, WI
}
Purpose
Obesity is a well-known risk factor for adverse cardiovascular events, but some studies suggest higher body mass index (BMI) is associated with better outcomes after ST-segment elevation myocardial infarction (STEMI). We sought to determine the effect of body surface area (BSA) on adverse events after primary percutaneous coronary intervention $(\mathrm{PCl})$ for STEMI and how this relates to the reported obesity paradox theory.

Methods We analyzed a prospective registry of patients with STEMI who underwent primary $\mathrm{PCl}$ at a tertiary care hospital from 2003 to 2009. Post-PCl complications and 1-year all-cause mortality were compared across BSA quartiles. Relationship with 1-year mortality was compared between BSA and BMI using logistic regression.

Results Of 2,195 study patients (31.5\% women), mean BSA and BMI were $2.0 \pm 0.3 \mathrm{~m}^{2}$ and $29.2 \pm 6.2 \mathrm{~kg} / \mathrm{m}^{2}$, respectively. The 1-year all-cause mortality from the lowest to highest quartiles of BSA was $11.0 \%, 6.5 \%$, $5.5 \%$ and $5.1 \%, P_{\text {trend }}<0.0001$. Over a mean 5 -year follow-up, there was a $76 \%$ relative risk reduction in death for each $1 \mathrm{~m}^{2}$ increase in BSA. Higher BSA was associated with lower incidence of cardiogenic shock, acute renal failure, coronary dissection and vascular and bleeding complications post-PCI. In multivariate analysis, BSA remained strongly predictive of 1-year mortality (odds ratio 0.4 per $\mathrm{m}^{2}$ of BSA, 95\% confidence interval 0.15-0.9), but BMI showed no independent association with mortality (odds ratio 0.99, 95\% confidence interval 0.95-1.04).

Conclusions In STEMI patients undergoing primary $\mathrm{PCl}$, high BSA is associated with lower mortality and complication rates. BMI is not independently associated with 1-year mortality after adjusting for BSA and sex. (J Patient-Centered Res Rev. 2015;2:9-16.)

Keywords body mass index, body size, mortality, myocardial infarction, coronary angioplasty

Primary percutaneous coronary intervention (PCI) is the gold standard approach to reperfusion therapy in patients with ST-segment elevation myocardial infarction (STEMI) when there are no contraindications. ${ }^{1}$ There are modifiable procedural and clinical factors that affect the outcome of primary $\mathrm{PCI},{ }^{2-4}$ but there also are patient characteristics like $\operatorname{sex}^{5,6}$ and body mass index $(\mathrm{BMI})^{7,8}$ that are associated with PCI outcomes. Despite multiple studies that have been done to determine the association between BMI and the outcome of PCI, there are still conflicting data

*Drs. Shetabi and Nfor are joint first authors on this report.

Correspondence: Suhail Allaqaband, MD,

2801 W. Kinnickinnic River Parkway, Suite \#840,

Milwaukee, WI, 53215, T: 414-649-3909, F: 414-649-3551,

Email: publishing3@aurora.org in this regard.9-12 For example, Sarno et al. studied 1,707 patients who underwent PCI and followed them for one year. ${ }^{13}$ They found that BMI of $>30 \mathrm{~kg} / \mathrm{m}^{2}$ was an independent factor for major cardiac events and stent thrombosis irrespective of stent type. On the other hand, a study of 6,560 patients with non-STEMI showed that patients with high BMI had better 30-day outcomes compared to patients with lower BMI, but the benefit was not present after 30 days and both groups had the same risk for primary endpoints (cardiovascular death, myocardial infarction and recurrent ischemia) when followed for one year. ${ }^{14}$

Obesity is a well-established risk factor for cardiovascular disease, ${ }^{15}$ hence findings of better prognosis in obese patients than in normal-weight patients who are treated for heart failure, coronary 
disease and peripheral artery disease led to the term "obesity paradox."16-20 This suggests that obesity is a marker for a different unidentified factor that confers favorable cardiovascular outcomes. A positive correlation has been shown between body surface area (BSA), BMI and coronary artery size., ${ }^{8,21}$ The calculations for BSA and BMI both use height and weight, which could lead to confounding between the two. BSA is reflective of body and organ sizes, whereas BMI is a measure of body fat. ${ }^{22}$ It is unclear how BSA relates to the "obesity paradox" debate. Particularly, the effect of BSA on outcomes after primary PCI in patients with STEMI has not been previously studied. We hypothesized that patients with high BSA who undergo primary PCI for STEMI will have a lower rate of adverse outcomes than those with low BSA. We also compared the strength of association between mortality after primary PCI and BSA to the strength of association with BMI.

\section{METHODS}

This was a nonrandomized, retrospective, registry-based study designed to test the association between BSA and clinical outcomes after PCI in patients presenting with STEMI. Local institutional review board approval was obtained prior to initiation of the study.

\section{Patients and Variables}

A consecutive population of all patients 18 years or older who presented at our tertiary care hospital with STEMI and were revascularized with primary PCI from January 2003 to December 2009 were included in the analysis. Data was extracted from the local National Cardiovascular Data Registry (NCDR) CathPCI Registry ${ }^{\circledR}$. Hospital medical records were reviewed and relevant clinical information manually extracted for each patient. The National Death Index was queried to identify all out-of-hospital deaths.

Standard NCDR data definitions (www.ncdr.com/ webncdr/cathpci) were used for all variables. The main independent variables were BMI, BSA and sex. BMI was calculated as weight (in kilograms) $/$ height $^{2}$ (in meters). The commonly used Mosteller formula calculated BSA in $\mathrm{m}^{2}$ as $\sqrt{(\text { weight }} \mathrm{x}$ height/3600), with weight in kilograms and height in meters. ${ }^{23}$ Outcome variables assessed were in-hospital death, post-PCI bleeding, coronary dissection, access-site vascular complications, cardiogenic shock and acute renal failure as well as death from any cause within one year. Adverse events were adjudicated by reviewing patients' electronic hospital records.

\section{Data Analysis}

There are no universal cut-offs for BSA, hence the study sample was divided into quartiles of BSA and data compared between quartiles. Continuous variables were expressed as mean \pm standard deviation and compared using ANOVA. Categorical variables were reported as percentages and compared using chi-square test. Linear association among BSA quartile outcomes was investigated using the linear applications of the ANOVA and chi-square tests. Logistic regression was used to compare outcomes across quartiles of BSA adjusting for baseline patient comorbidities. Overall survival was compared among quartiles of BSA using Kaplan-Meier analysis and the log-rank test. Cox proportional hazards regression was used to analyze long-term survival. In survival analysis, time was measured beginning from the index primary PCI. All P-values were two-sided.

\section{RESULTS}

There were 2,197 patients who underwent primary PCI for STEMI during the 7-year study period. Their baseline characteristics are shown in Table 1. Mean age was $61.5 \pm 13.1$ years, and there was a significant trend for BSA to decrease with increasing age. There was a strong association between sex and BSA. The proportion of women per BSA quartile decreased progressively from lowest to highest quartile. There was a strong correlation between BSA and BMI. Figure 1 shows that this correlation was strong in both male and female patients. Interestingly, however, at every level of BMI, BSA was higher in men than in women. The frequency of hypertension, smoking, prior myocardial infarction and prior PCI was similar across all quartiles of BSA. Cardiac symptomatology was similar between BSA quartiles, with about $82 \%$ arriving within 6 hours of symptom onset and 7\% presenting with cardiogenic shock. Overall, $81 \%$ of patients had door-to-balloon time of $<90$ minutes and there was a small but statistically significant difference between the lowest and highest quartiles. There was no difference in the arterial territory or number of lesions revascularized, or in the number of stents used. Mean stent diameter increased with increasing BSA. There was a significant correlation between BSA and stent 
Table 1. Baseline patient characteristics in all patients and according to quartile of body surface area

\begin{tabular}{|c|c|c|c|c|c|c|}
\hline \multirow[b]{2}{*}{ Variable } & \multirow[b]{2}{*}{$\begin{array}{c}\text { All patients } \\
(\mathrm{N}=2,197)\end{array}$} & \multicolumn{5}{|c|}{ Body surface area, $\mathrm{m}^{2}$} \\
\hline & & $\begin{array}{c}<1.8 \\
(n=437)\end{array}$ & $\begin{array}{l}1.8 \text { to } 2 \\
(n=590)\end{array}$ & $\begin{array}{c}>2 \text { to } 2.2 \\
(n=586)\end{array}$ & $\begin{array}{c}>2.2 \\
(n=584)\end{array}$ & $P^{*}$ \\
\hline Age (years), mean \pm SD & $61.5 \pm 13.1$ & $69.5 \pm 13.9$ & $63.3 \pm 12.8$ & $59.3 \pm 11.5$ & $55.9 \pm 10.9$ & $<0.001$ \\
\hline Female, \% & 31.2 & 74.4 & 34.6 & 17.6 & 9.1 & $<0.001$ \\
\hline BMI $\left(\mathrm{kg} / \mathrm{m}^{2}\right)$, mean \pm SD & $29.2 \pm 6.1$ & $24.2 \pm 6.0$ & $27.1 \pm 3.5$ & $29.8 \pm 4.5$ & $34.5 \pm 5.4$ & $<0.001$ \\
\hline Smoker, \% & 44.8 & 37.7 & 46.9 & 46.9 & 45.9 & 0.11 \\
\hline Hypertension, \% & 57.9 & 61.1 & 55.5 & 56.0 & 59.9 & 0.16 \\
\hline Dyslipidemia, \% & 62.0 & 55.2 & 60.1 & 65.4 & 65.6 & 0.001 \\
\hline Diabetes, \% & 16.9 & 15.8 & 14.9 & 15.5 & 21.1 & 0.05 \\
\hline Previous MI, \% & 16.0 & 19.8 & 14.9 & 15.2 & 14.9 & 0.12 \\
\hline Previous $\mathrm{PCl}, \%$ & 21.4 & 22.5 & 20.7 & 22.0 & 20.5 & 0.83 \\
\hline Previous CABG, \% & 5.6 & 5.7 & 7.5 & 6.3 & 2.7 & 0.004 \\
\hline Symptom duration & & & & & & 0.28 \\
\hline$\leq 6$ hours, $\%$ & 82.0 & 76.9 & 83.5 & 81.4 & 84.8 & \\
\hline $6-12$ hours, $\%$ & 8.7 & 11.0 & 8.2 & 8.6 & 7.7 & \\
\hline$>12$ hours, $\%$ & 9.3 & 12.1 & 8.2 & 10.1 & 7.5 & \\
\hline Door-to-balloon time <90 min, \% & 81.1 & 76.4 & 81.7 & 83.3 & 81.8 & 0.04 \\
\hline Transfer patient, \% & 49.6 & 49.5 & 43.4 & 50.7 & 54.8 & 0.01 \\
\hline Cardiogenic shock, \% & 7.1 & 8.2 & 6.6 & 6.7 & 7.0 & 0.74 \\
\hline LVEF $\leq 40, \%$ & 33.2 & 40.4 & 34.3 & 30.8 & 29.3 & 0.04 \\
\hline \multicolumn{7}{|l|}{ Arteries revascularized ${ }^{\dagger}$} \\
\hline Left main, \% & 0.5 & 0.7 & 0.2 & 0.7 & 0.7 & 0.55 \\
\hline Left anterior descending, $\%$ & 38.3 & 41.0 & 38.0 & 35.8 & 39.0 & 0.39 \\
\hline Left circumflex, \% & 19.2 & 17.6 & 18.8 & 21.3 & 18.5 & 0.45 \\
\hline Right coronary, \% & 49.4 & 48.1 & 50.3 & 51.2 & 47.8 & 0.59 \\
\hline Lesions treated $(n)$, mean $\pm S D$ & $1.3 \pm 0.6$ & $1.3 \pm 0.6$ & $1.3 \pm 0.6$ & $1.4 \pm 0.7$ & $1.3 \pm 0.5$ & 0.16 \\
\hline Stents $(n)$, mean \pm SD & $1.7 \pm 1.0$ & $1.6 \pm 1.1$ & $1.7 \pm 1.2$ & $1.7 \pm 1.0$ & $1.6 \pm 0.9$ & 0.53 \\
\hline Stent diameter $(\mathrm{mm})$, mean $\pm \mathrm{SD}$ & $3.0 \pm 0.5$ & $2.9 \pm 0.4$ & $3.0 \pm 0.4$ & $3.1 \pm 0.5$ & $3.3 \pm 0.3$ & $<0.001$ \\
\hline Bare-metal stent, \% & 46.6 & 49.0 & 44.7 & 45.1 & 48.3 & 0.39 \\
\hline Drug-eluting stent, \% & 41.1 & 34.6 & 43.4 & 43.9 & 41.1 & 0.01 \\
\hline Unknown stent type, \% & 12.2 & 16.5 & 11.9 & 11.1 & 10.6 & 0.02 \\
\hline
\end{tabular}

*Two-tailed P-value calculated using chi-square test for categorical variables and ANOVA for continuous variables.

${ }^{+}$Adds up to more than $100 \%$ because some patients had more than one artery revascularized

$B M I$, body mass index; CABG, coronary artery bypass graft; LVEF, left ventricular ejection fraction; MI, myocardial infarction; $\mathrm{PCl}$, percutaneous coronary intervention; $S D$, standard deviation.

diameter $(\mathrm{R}=0.26, \mathrm{P}<0.001)$. Using linear regression analysis, stent diameter increased by $0.29 \mathrm{~mm}$ for each $1 \mathrm{~m}^{2}$ increase in BSA $(95 \%$ confidence interval $[\mathrm{CI}]$ $0.2-0.37, \mathrm{P}<0.001)$.

Overall angiographic success, defined as residual stenosis of $<30 \%$ with TIMI-3 flow, was $97.5 \%$, and was similar across all BSA quartiles $(\mathrm{P}=0.69)$. There were some significant differences in post-PCI clinical outcomes between BSA quartiles (Figure 2). There was a significant inverse linear relationship between post-PCI complications and BSA quartile. The rate of adverse events decreased from lowest $\left(\leq 1.8 \mathrm{~m}^{2}\right)$ to highest BSA quartile $\left(>2.2 \mathrm{~m}^{2}\right)$. Although coronary dissection was generally rare, it had the highest relative increase, 27-fold from the highest BSA quartile to the 
lowest quartile. There was approximately a doubling in the incidence of acute renal failure, vascular complications (mainly pseudoaneurysms), bleeding events and cardiogenic shock between the highest and lowest BSA quartiles. The incidence of repeat myocardial infarction prior to discharge was $0.8 \%$ overall, without any difference between BSA quartiles $(\mathrm{P}=0.16)$. The rates of emergency coronary artery bypass surgery were $2.7 \%, 2.5 \%, 1.9 \%$ and $2.6 \%$ in the lowest, second, third and highest quartiles, respectively $(\mathrm{P}=0.95)$.

These differences in post-PCI complications were accompanied by a significant decrease in mortality with increasing BSA. In-hospital mortality was $7.4 \%, 4.6 \%$, $3.4 \%$ and $3.4 \%$ in the lowest, second, third and highest BSA quartiles, respectively ( $\mathrm{P}=0.001)$. In patients with STEMI, the better prognosis associated with high BSA that is seen early after primary PCI persisted long term. Figure 3 shows Kaplan-Meier survival curves for the four quartiles of BSA. The 1-year overall survival rates were $88.3 \%, 93.7 \%, 94.5 \%$ and $94.9 \%$ in the lowest, second, third and highest BSA quartiles, respectively $\left(\mathrm{P}_{\text {trend }}<0.001\right)$. Over a mean follow-up period of 5 years (range: 2-9 years), the hazard ratios of all-cause death in the second, third and highest quartiles of BSA when compared to the lowest quartile were $0.63(95 \% \mathrm{CI}$ $0.46-0.87), 0.48$ (95\% CI $0.34-0.68)$ and 0.43 (95\% CI 0.31-0.62). Considering BSA as a continuous variable, there was a $76 \%$ relative risk reduction in death for every $1 \mathrm{~m}^{2}$ increase in BSA (95\% CI 61.085.0, $\mathrm{P}<0.001)$.

We compared the strengths of association of BSA with 1-year mortality and the association of BMI with 1-year mortality (Table 2). On univariate analysis, increases in both BSA and BMI were associated with decreases in 1-year mortality, but the association was stronger with BSA than BMI. We performed multivariate analysis adjusting for BSA, BMI and sex because all three variables affect each other and mortality. We also adjusted for age, symptom duration, shock, door-toballoon time, coronary anatomy and comorbidities. BSA maintained a significant independent association with 1-year mortality, but BMI and sex were no longer associated with 1-year mortality.

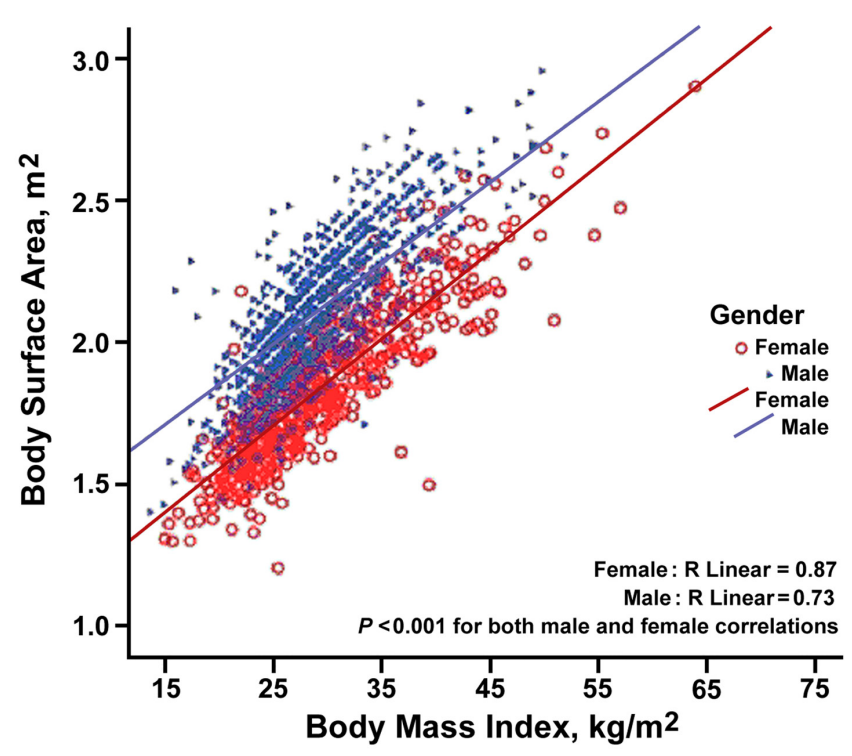

Figure 1. Correlation of body surface area with body mass index among male and female patients. $R$ stands for correlation coefficient. Each data point represents a patient. Lines represent the linear correlation relationship.
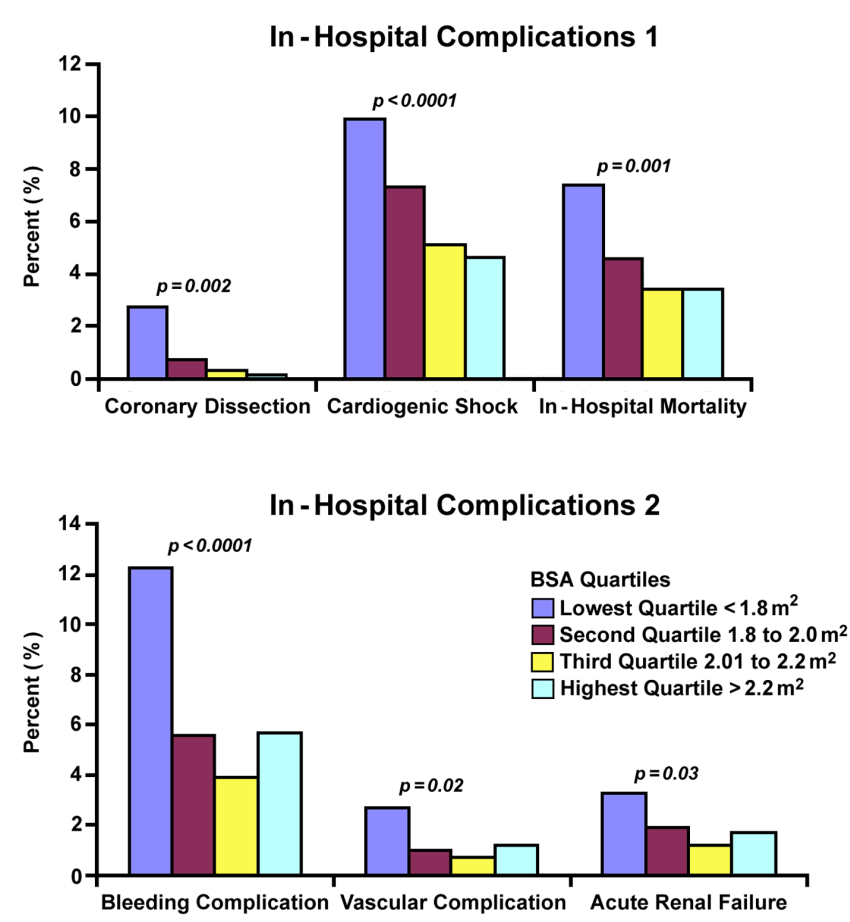

Figure 2. Comparison of in-hospital adverse events occurring after primary percutaneous coronary intervention in patients with ST-elevation myocardial infarction between quartiles of body surface area (BSA). 


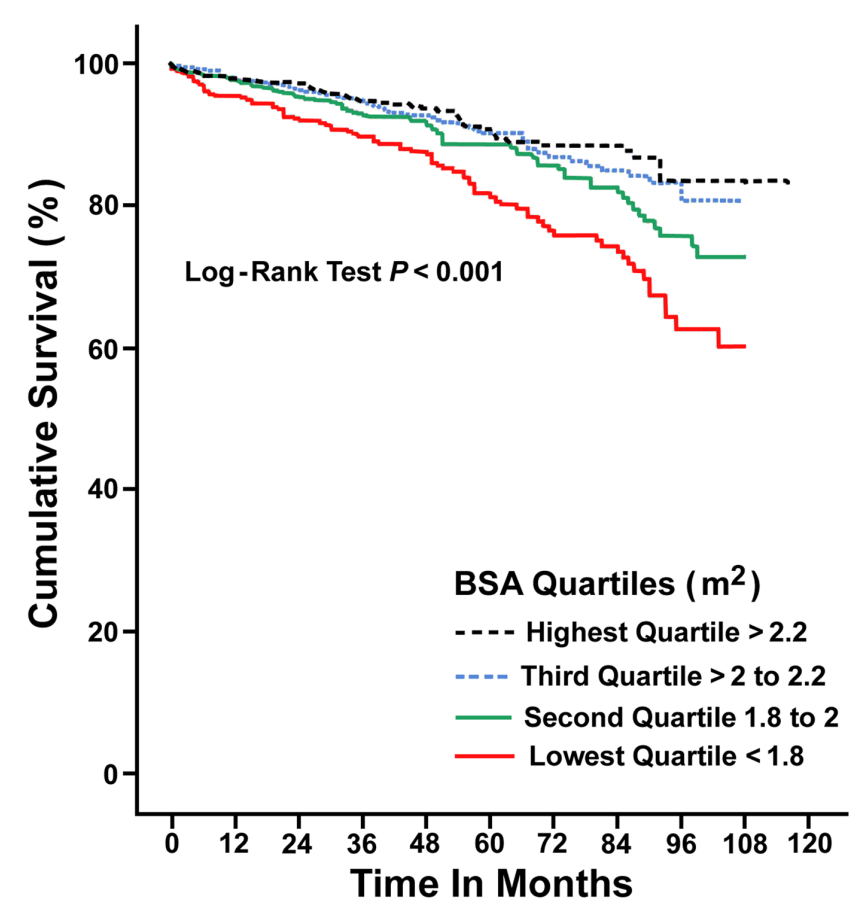

Figure 3. Kaplan-Meier curves comparing overall survival between quartiles of body surface area (BSA).

\section{DISCUSSION}

In this study we divided 2,197 patients with STEMI who underwent primary PCI into quartiles of BSA and compared clinical outcomes between them. Going form the lowest $\left(<1.8 \mathrm{~m}^{2}\right)$ to the highest quartile $\left(>2.2 \mathrm{~m}^{2}\right)$ of BSA, there were significant reductions in post-PCI complications like coronary dissection, cardiogenic shock, acute renal failure, bleeding, vascular complications and in-hospital death. Long- term all-cause mortality also decreased with increasing BSA. BMI was associated with 1-year mortality only on univariate analysis. In the multivariate analysis, only BSA remained associated with 1-year mortality whereas BMI showed no independent effect.

Previous studies have investigated the association between BMI and PCI outcomes in patients with acute coronary syndromes and reported results that are in conflict with the obesity paradox. ${ }^{7,8,12,24}$ In a study of 4,972 patients who underwent PCI with drug-eluting stents, patients with higher BMI had a higher risk of stent thrombosis compared to patients with lower BMI; and after multivariate analysis, obesity was still an independent predictor for thrombotic events. ${ }^{12}$ Similarly, Ellis et al. evaluated the association of BMI and PCI outcomes on 3,571 patients and showed BMI of $>35$ was associated with higher mortality. ${ }^{24}$

Different mechanisms have been proposed to explain these findings. First, obese patients have higher levels of coagulation factors, including factors VII, VIII, plasminogen activator inhibitor-1 and fibrinogen, that make them relatively hypercoagulable. ${ }^{25,26}$ Periprocedural antithrombotic regimens may be inadequate in very obese patients due to their unusual weight. ${ }^{24,27}$ Other studies have paradoxically shown that higher BMI was associated with better outcomes in patients who undergo PCI, lending support to the obesity paradox. ${ }^{8-11}$ Obesity has long been associated with an increased risk of death from all causes, diabetes mellitus, hypertension, dyslipidemia and atherosclerosis. $^{28,29}$ These well-documented adverse outcomes of obesity lead us to think that the observation

Table 2. Relative strengths of association of body surface area and body mass index with 1-year mortality

\begin{tabular}{lccccccc}
\hline & \multicolumn{3}{c}{ Univariate } & & \multicolumn{3}{c}{ Multivariate adjusted } \\
\cline { 2 - 4 } Variable & Odds ratio & $\mathbf{9 5 \%} \mathbf{C l}$ & $\boldsymbol{P}$ & & Odds ratio & $\mathbf{9 5 \%} \mathrm{Cl}$ & $\boldsymbol{P}$ \\
\hline Body surface area $\left(\mathrm{m}^{2}\right)^{\dagger}$ & 0.24 & $0.13-0.45$ & $<0.0001$ & & 0.40 & $0.15-0.90$ & 0.01 \\
Body mass index $\left(\mathrm{kg} / \mathrm{m}^{2}\right)^{\dagger}$ & 0.96 & $0.93-0.99$ & 0.019 & & 0.99 & $0.95-1.04$ & 0.82 \\
Male $^{\S}$ & 0.51 & $0.36-0.71$ & $<0.0001$ & & 0.68 & $0.43-1.07$ & 0.10 \\
\hline
\end{tabular}

${ }^{*}$ Adjusted for listed variables plus age, symptom duration, shock, door-to-balloon time, coronary anatomy and comorbidities.

+Odds ratios calculated per unit increase in body surface area or body mass index.

$\S$ Compares male versus female.

Cl, confidence interval. 
of better post-PCI outcomes in obese patients is due to some other confounding factor. More recent studies have questioned the validity of an obesity paradox in patients treated with PCI. In the Swedish Coronary Angiography and Angioplasty Study, there was a biphasic relationship between BMI and mortality in which mortality decreased with increasing BMI up to $35 \mathrm{~kg} / \mathrm{m}^{2}$, after which mortality started to increase. ${ }^{30} \mathrm{~A}$ recent study of patients with STEMI from the NCDR registry also reported lower in-hospital mortality, bleeding and adverse cardiac events with increasing BMI, except for patients with BMI of $>40 \mathrm{~kg} / \mathrm{m}^{2}$, who had worse prognosis. ${ }^{31}$ In this study, however, obese patients were more likely to be younger and have less extensive coronary artery disease. After adjustment for baseline differences, there was no significant difference in outcomes between normal-weight, overweight and mildly obese patients, putting into question the obesity paradox.

Our study also found that while mortality decreased with increasing BMI on univariate analysis, BMI had no effect on mortality on multivariate analysis that adjusted for baseline confounders. BSA, on the other hand, maintained a strong association with mortality both in unadjusted and adjusted analyses. The strong correlation we demonstrated between BSA and BMI show the confounding effect they have on each other. This leads us to propose that much of the previously observed association between BMI and prognosis after myocardial infarction or PCI can be attributed to the confounding effect of BSA. We suggest that BSA is the true independent predictor of outcomes after primary PCI in patients with STEMI.

Although there are no studies that directly test the effect of BSA on post-PCI outcomes, there have been indirect inferences in recent literature. In a large study based on the NCDR registry with an identical definition of bleeding to ours, the bleeding risk after PCI was not associated to BMI but was decreased with increase in BSA. ${ }^{32}$ Bleeding risk of women was double that of men $(7.8 \%$ vs. $3.7 \%, \mathrm{P}<0.01)$, which was attributable in part to lower BSA of women. Similarly, Peterson et al. evaluated 109,708 patients treated with PCI and reported a higher risk for stroke, vascular complications and in-hospital mortality in women than men, but there was no difference in mortality after adjusting for BSA. ${ }^{5}$
The authors concluded that BSA, rather than sex, is an independent risk factor for post-PCI mortality. There is a well-demonstrated association between high BSA and better outcomes after coronary artery bypass grafting (CABG). High BSA is associated with better graft patency, leading to lower incidence of adverse cardiac events after $\mathrm{CABG} .{ }^{33}$ There is strong evidence showing that BSA and coronary artery diameter are inversely related with mortality rate in patients who undergo $\mathrm{CABG} .{ }^{34,35}$ Much of the reports of higher mortality in women compared to men after CABG have been attributed to the smaller BSA of women. ${ }^{36,37}$

The positive effect of BSA on coronary artery diameter, cardiac size and blood volume may explain the effect of BSA on post-PCI outcomes. In populations of patients both with and without established coronary artery disease, there is a significant increase in the diameter of coronary arteries with increasing BSA irrespective of sex. ${ }^{6,21}$ If stent diameter can be used as a surrogate for coronary artery diameter, this will be similar to our finding of a positive correlation between stent diameter and BSA. In the PCI population, large coronary diameter was associated with lower rates of restenosis, repeat revascularization, stent thrombosis, recurrent myocardial infarction and death. ${ }^{38,39}$ In the general population, BSA has correlated positively with other measures of heart size like left ventricular mass, ventricular volumes and blood volume..$^{40-42}$ Larger arteries also prevent sheath/artery mismatch, which reduces access site complications. We theorize that prognosis is better in patients with high BSA after primary PCI following STEMI because they have more myocardial and vascular reserve that can compensate for the injury acutely as well as larger coronary arteries that lower the risk of cardiac events.

\section{Limitations}

Our study reflects the experience of a tertiary care center with a rare STEMI program that requires the catheterization laboratory staff and interventional cardiologist to remain in-house 24 hours/day, 7 days/ week. ${ }^{43}$ Although our overall event rates may be different from other centers, we do not anticipate a different relationship between BSA and major outcomes. The use of a registry could introduce errors due to missing data and inaccurate data entry. We manually reviewed hospital records to crosscheck clinical 
outcomes on every patient. Bleeding complications captured in our study were major ones associated with drop in hemoglobin of $\geq 3 \mathrm{~g} / \mathrm{dL}$, blood transfusion or procedural intervention to control bleeding. Less significant bleeding events, albeit important, were not captured. That said, our findings are valid and constitute an important consideration for clinicians when caring for patients with STEMI.

\section{CONCLUSIONS}

There is an inverse relationship between body surface area and adverse clinical events in patients with ST-segment elevation myocardial infarction who undergo primary percutaneous coronary intervention. Increase in BSA from the lowest to highest quartile was associated with decreasing rates of short- and longterm mortality as well as decreasing rates of coronary dissection, cardiogenic shock, acute renal failure, bleeding and vascular complications. Body mass index is not independently associated with 1-year mortality after adjusting for BSA and sex. Clinicians should pay attention to the increased risk of adverse outcomes in patients with BSA of $<1.8 \mathrm{~m}^{2}$, and consideration should be given to including BSA in risk adjustment models that compare clinical outcomes in patients undergoing primary PCI for STEMI.

\section{Patient-Friendly Recap}

- A heart attack (myocardial infarction) occurs when proper blood flow to the heart is stopped, usually due to blockage in one or more coronary arteries.

- Percutaneous coronary intervention (PCI) is a less invasive procedure used to unclog arteries and prevent further heart damage.

- Despite having an overall increased risk of heart disease, obese patients seem to do better following PCI.

- The authors report this "obesity paradox" can be attributed to increased body surface area, rather than body mass index (BMI) as previously reported.

- Patients with more body surface area tend to have wider arteries, which might explain why they experience fewer complications from PCI.

\section{Acknowledgments}

The authors gratefully acknowledge Brian Miller and Brian Schurrer of Aurora Sinai Medical Center for their help with figures.

\section{Conflicts of Interest}

None.

\section{REFERENCES}

1. Keeley EC, Boura JA, Grines CL. Primary angioplasty versus intravenous thrombolytic therapy for acute myocardial infarction: a quantitative review of 23 randomised trials. Lancet. 2003;361:13-20.

2. McNamara RL, Wang Y, Herrin J, et al. Effect of door-toballoon time on mortality in patients with ST-segment elevation myocardial infarction. J Am Coll Cardiol. 2006;47:2180-6.

3. Gale CP, Manda SO, Batin PD, Weston CF, Birkhead JS, Hall AS. Predictors of in-hospital mortality for patients admitted with ST-elevation myocardial infarction: a real-world study using the Myocardial Infarction National Audit Project (MINAP) database. Heart. 2008;94:1407-12.

4. DeGeare VS, Boura JA, Grines LL, O’Neill WW, Grines CL. Predictive value of the Killip classification in patients undergoing primary percutaneous coronary intervention for acute myocardial infarction. Am J Cardiol. 2001;87:1035-8.

5. Peterson ED, Lansky AJ, Kramer J, Anstrom K, Lanzilotta MJ; National Cardiovascular Network Clinical Investigators. Effect of gender on the outcomes of contemporary percutaneous coronary intervention. Am J Cardiol. 2001;88:359-64.

6. Kim SG, Apple S, Mintz GS, et al. The importance of gender on coronary artery size: in-vivo assessment by intravascular ultrasound. Clin Cardiol. 2004;27:291-4.

7. Powell BD, Lennon RJ, Lerman A, et al. Association of body mass index with outcome after percutaneous coronary intervention. Am J Cardiol. 2003;91:472-6.

8. Gurm HS, Whitlow PL, Kip KE, BARI Investigators. The impact of body mass index on short- and long-term outcomes in patients undergoing coronary revascularization. Insights from the bypass angioplasty revascularization investigation (BARI). J Am Coll Cardiol. 2002;39:834-40.

9. Gruberg L, Weissman NJ, Waksman R, et al. The impact of obesity on the short-term and long-term outcomes after percutaneous coronary intervention: the obesity paradox? J Am Coll Cardiol. 2002;39:578-84.

10. Gurm HS, Brennan DM, Booth J, Tcheng JE, Lincoff AM, Topol EJ. Impact of body mass index on outcome after percutaneous coronary intervention (the obesity paradox). Am J Cardiol. 2002;90:42-5.

11. Minutello RM, Chou ET, Hong MK, et al. Impact of body mass index on in-hospital outcomes following percutaneous coronary intervention (report from the New York State Angioplasty Registry). Am J Cardiol. 2004;93:1229-32.

12. Wang ZJ, Zhou YJ, Liu YY, et al. Obesity and cardiovascular thrombotic events in patients undergoing percutaneous coronary intervention with drug-eluting stents. Heart. 2009;95:1587-92.

13. Sarno G, Garg S, Onuma Y, et al. The impact of body mass index on the one year outcomes of patients treated by percutaneous coronary intervention with Biolimus- and 
Sirolimus-eluting stents (from the LEADERS trial). Am $J$ Cardiol. 2010;105:475-9.

14. Kadakia MB, Fox CS, Scirica BM, Murphy SA, Bonaca MP, Morrow DA. Central obesity and cardiovascular outcomes in patients with acute coronary syndrome: observations from the MERLIN-TIMI 36 trial. Heart. 2011;97:1782-7.

15. Yusuf S, Hawken S, Ounpuu S, et al. Obesity and the risk of myocardial infarction in 27,000 participants from 52 countries: a case-control study. Lancet. 2005;366:1640-9.

16. Fonarow GC, Srikanthan P, Costanzo MR, Cintron GB, Lopatin M; ADHERE Scientific Advisory Committee and Investigators. An obesity paradox in acute heart failure: analysis of body mass index and inhospital mortality for 108,927 patients in the Acute Decompensated Heart Failure National Registry. Am Heart J. 2007;153:74-81.

17. Artham SM, Lavie CJ, Milani RV, Ventura HO. The obesity paradox: impact of obesity on the prevalence and prognosis of cardiovascular diseases. Postgrad Med. 2008;120:34-41.

18. Lavie CJ, Milani RV, Ventura HO. Obesity and cardiovascular disease: risk factor, paradox, and impact of weight loss. $J \mathrm{Am}$ Coll Cardiol. 2009;53:1925-32.

19. Lancefield T, Clark DJ, Andrianopoulos N, et al. Is there an obesity paradox after percutaneous coronary intervention in the contemporary era? An analysis from a multicenter Australian registry. JACC Cardiovasc Interv. 2010;3:660-8.

20. Tercius AJ, Nfor T, Mori N, et al. Impact of body surface area on outcomes in patients with lower extremity peripheral arterial disease. (abstr.) J Am Coll Cardiol. 2012;60:B44.

21. Sheifer SE, Canos MR, Weinfurt KP, et al. Sex differences in coronary artery size assessed by intravascular ultrasound. Am Heart J. 2000;139:649-53.

22. Deurenberg P, Weststrate JA, Seidell JC. Body mass index as a measure of body fatness: age- and sex-specific prediction formulas. Br J Nutr. 1991;65:105-14.

23. Mosteller RD. Simplified calculation of body-surface area. N Engl J Med. 1987;317:1098.

24. Ellis SG, Elliott J, Horrigan M, Raymond RE, Howell G. Low-normal or excessive body mass index: newly identified and powerful risk factors for death and other complications with percutaneous coronary intervention. Am $J$ Cardiol. 1996;78:642-6.

25. Cushman M, Yanez D, Psaty BM, et al. Association of fibrinogen and coagulation factors VII and VIII with cardiovascular risk factors in the elderly: the Cardiovascular Health Study. Cardiovascular Health Study Investigators. Am J Epidemiol. 1996;143:665-76.

26. Reiner AP, Siscovick DS, Rosendaal FR. Hemostatic risk factors and arterial thrombotic disease. Thromb Haemost. 2001;85:584-95.

27. Sibbing D, von Beckerath O, Schömig A, Kastrati A, von Beckerath N. Impact of body mass index on platelet aggregation after administration of a high loading dose of 600 $\mathrm{mg}$ of clopidogrel before percutaneous coronary intervention. Am J Cardiol. 2007;100:203-5.

28. Calle EE, Thun MJ, Petrelli JM, Rodriguez C, Heath CW Jr. Body-mass index and mortality in a prospective cohort of U.S. adults. N Engl J Med. 1999;341:1097-105.

29. Allison DB, Fontaine KR, Manson JE, Stevens J, VanItallie TB. Annual deaths attributable to obesity in the United States. JAMA. 1999;282:1530-8.
30. Angerås O, Albertsson P, Karason K, et al. Evidence for obesity paradox in patients with acute coronary syndromes: a report from the Swedish Coronary Angiography and Angioplasty Registry. Eur Heart J. 2013;34:345-53.

31. Das SR, Alexander KP, Chen AY, et al. Impact of body weight and extreme obesity on the presentation, treatment, and in-hospital outcomes of 50,149 patients with ST-segment elevation myocardial infarction results from the NCDR (National Cardiovascular Data Registry). J Am Coll Cardiol. 2011;58:2642-50.

32. Daugherty SL, Thompson LE, Kim S, et al. Patterns of use and comparative effectiveness of bleeding avoidance strategies in men and women following percutaneous coronary interventions: an observational study from the National Cardiovascular Data Registry. $\mathrm{J} \mathrm{Am} \mathrm{Coll} \mathrm{Cardiol.}$ 2013;61:2070-8.

33. Gruberg L, Mercado N, Milo S, et al. Impact of body mass index on the outcome of patients with multivessel disease randomized to either coronary artery bypass grafting or stenting in the ARTS trial: the obesity paradox II? Am J Cardiol. 2005;95:439-44.

34. Fisher LD, Kennedy JW, Davis KB, et al. Association of sex, physical size, and operative mortality after coronary artery bypass in the Coronary Artery Surgery Study (CASS). J Thorac Cardiovasc Surg. 1982;84:334-41.

35. O'Connor GT, Morton JR, Diehl MJ, et al. Differences between men and women in hospital mortality associated with coronary artery bypass graft surgery. The Northern New England Cardiovascular Disease Study Group. Circulation. 1993;88:2104-10.

36. Craddock D, Iyer VS, Russell WJ. Factors influencing mortality and myocardial infarction after coronary artery bypass grafting. Curr Opin Cardiol. 1994;9:664-9.

37. Christakis GT, Weisel RD, Buth KJ, et al. Is body size the cause for poor outcomes of coronary artery bypass operations in women? J Thorac Cardiovasc Surg. 1995;110:1344-56; discussion 1356-8.

38. Kuchulakanti PK, Chu WW, Torguson R, et al. Correlates and long-term outcomes of angiographically proven stent thrombosis with sirolimus- and paclitaxel-eluting stents. Circulation. 2006;113:1108-13.

39. van Werkum JW, Heestermans AA, Zomer AC, et al. Predictors of coronary stent thrombosis: the Dutch Stent Thrombosis Registry. J Am Coll Cardiol. 2009;53:1399-409.

40. de Simone G, Daniels SR, Devereux RB, et al. Left ventricular mass and body size in normotensive children and adults: assessment of allometric relations and impact of overweight. J Am Coll Cardiol. 1992;20:1251-60.

41. Ilercil A, O’Grady MJ, Roman MJ, et al. Reference values for echocardiographic measurements in urban and rural populations of differing ethnicity: the Strong Heart Study. J Am Soc Echocardiogr. 2001;14:601-11.

42. Lang RM, Bierig M, Devereux RB, et al. Recommendations for chamber quantification. Eur $J$ Echocardiogr. 2006;7: 79-108.

43. Allaqaband S, Jan MF, Banday WY, et al. Impact of 24-hr in-hospital interventional cardiology team on timeliness of reperfusion for ST-segment elevation myocardial infarction. Catheter Cardiovasc Interv. 2010;75:1015-23.

(C) 2015 Aurora Health Care, Inc. 